\title{
Challenging Inclusivity Urban Agriculture and Community Involvement in San Diego
}

\author{
Bruno Monardo ${ }^{1, a}$, Anna Laura Palazzo $2, b$ \\ '‘Sapienza' University of Rome, Via Flaminia 70, 00196 Rome, Italy \\ 2‘Roma Tre' University of Rome, Via Madonna dei Monti 40, 00184 Rome, Italy \\ abruno.monardo@uniroma1.it, bannalaura.palazzo@uniroma3.it
}

Keywords: Social Inclusion, Urban Agriculture, Healthy Food System, Urban Regeneration.

\begin{abstract}
In recent years, destiny of cities has proven to be connected to efficiency and resilience of their 'Green Infrastructures', related agri-forestry strategies and health and food security policies. Policy-makers are increasingly dealing with such issues by means of specific sectorial measures including food system arrangements for health and sustainability, even in order to preserve fringe areas threatened by urban growth. Across the US, where 'food deserts' heavily shape access to fresh, local and healthy food, the growing consumers' demand is being addressed by Urban Agriculture practices giving new perspectives to blighted zones of the post-crisis cities and tackling social malaise related to the massive migration. The 'New Roots Community Farm' in City Heights neighbourhood, San Diego, California, shows an intriguing potential, matching social inclusion and physical-economic redevelopment.
\end{abstract}

\section{The 'Healthy Food' issue in the United States}

There is no doubt that since the very beginning of the Structural fund season, the European Union has been increasingly pursuing principles of community cohesion and social inclusion and an important role for reaching the expected outputs was reserved to territorial and urban redevelopment. Europe 2020 strategy has been conceived in order to re-boost the integration of 'civitas' and 'urbs' dimensions providing a new impulse to the centrality of urban and metropolitan areas. As part of this issue, the 'Healthy food system' and the 'Urban Agriculture' (UA) phenomenon - the culture of which has its roots in the history of European settlements - can represent an intriguing vector for integrating economic, environmental and space issues with social inclusion imperatives in contemporary urban policy. There is no doubt that this is a complex, relevant challenge, nevertheless it may be argued that it is possible to explore new fruitful paths, highlighted by intriguing, successful practices belonging to other cultural contexts.

Urban redevelopment within cities affected by economic crises currently presents a major challenge for public administrations, private investors, and an increasingly kaleidoscopic group of socially-driven stakeholders. However, the imperative of pursuing inclusive urban strategies which are faced with the exponential rise in migration has rarely been connected to the issues of limiting land consumption and boosting economic, physical and social regeneration in most developed countries. Only fairly recently within the general framework of urban/rural relationships has UA begun to emerge as a practice that could prove successful both for giving new perspectives to blighted zones of crisis-ridden and post-crisis cities, and for tackling the kind of social malaise related to the phenomenon of mass migration in western metropolitan areas.

This work focuses on reflecting on and assessing how - and to what extent - the so called Healthy food policy and the related UA practices in United States (and particularly in San Diego, California) can drive innovation in urban regeneration strategies, not only in physical and economic terms, but also from the perspective of social inclusion culture. A specific case study of an integrated initiative run by a non-profit organization (NPO) is discussed in order to support such a scenario. The New Roots Community Farm initiative - located in a 'patchwork community' of immigrants in the distressed neighbourhood of City Heights - seems to be particularly significant for its aim of revitalizing 'rurban' spaces through the involvement of refugee groups and the related 
local community in urban farming, community garden care, and the potential for an interesting 'chain' of connected activities. The entire neighbourhood is considered a 'critical food access' area and the main engine of the initiative, an international NPO - the International Rescue Committee (IRC) - worked with other community-based associations, the City of San Diego and the San Diego County Farm Bureau to develop the project on vacant public land. This 'lesson' can represent a significant experience in order to assess critically how and to what extent the 'feeding the city' approach can positively impact on urban regeneration strategies both in American and European contexts.

\section{Food deserts: a geography of discomfort in the US}

All over the US, a brand new 'geography of discomfort' is significantly challenging a broader meaning of Welfare State by featuring goal standards in food access. A growing consumer demand for fresh, local and healthy food is creating new markets and changing relationships and flows between urban, peri-urban and rural contexts. Many of these efforts specifically address the needs of residents of low-income urban neighbourhoods to access food. The wider framework in which such programs are embedded is to be found in the so called 'Healthy food policies' and proper diet habits as a way to tackle such serious and widespread social diseases as obesity, diabetes, cardiovascular problems and specific types of cancer.

Although US food production is significantly more than sufficient - almost triple the present needs of consumers [1] - the entanglement of malnutrition and lack of access to fresh and healthy food is the main issue at hand. Indeed, not only does disciplinary research literature demonstrate a correlation between the health behaviour of individuals and their social and physical surroundings,

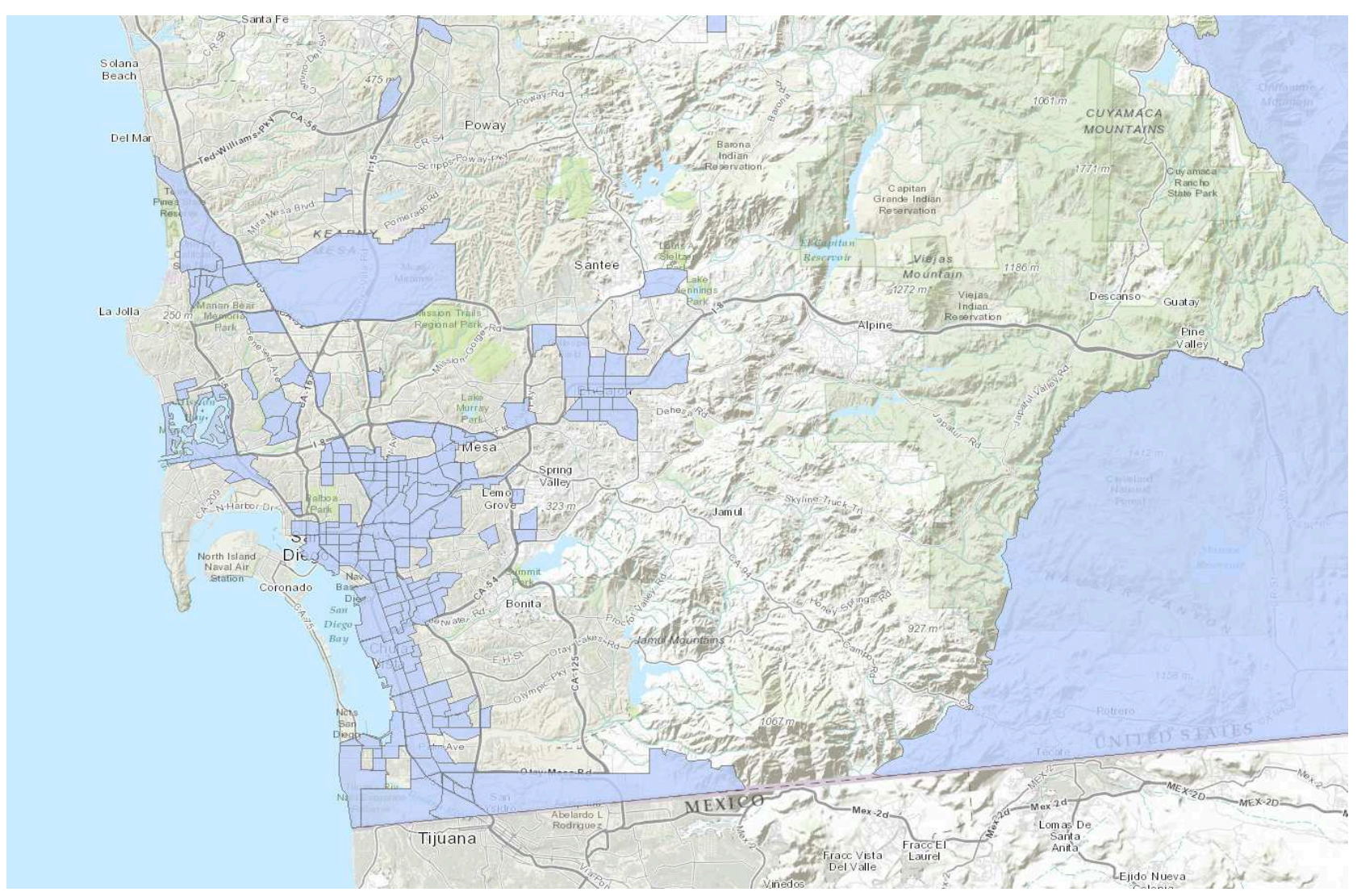

Fig. 1. Food access locator. Tracts with a poverty rate of $20 \%$ or higher, or tracts with a median family income less than $80 \%$ of median family income for the State or metropolitan area. Source [4]. 
but specifically shows a relationship between diseases of malnutrition and low-income neighbourhoods.

The lack of supermarkets and grocery stores selling affordable, fresh, healthy food may have substantial impact on low-income and minority communities to have equal access to food [2].

Thus, the most compelling argument in favour of widespread availability of fresh and healthy food is reflected in the mapping of 'food access', where 'food deserts' are areas "with limited access to affordable and nutritious food" [3] - or 'food swamps' are marked by the abundance of unhealthy food sources such as fast-food restaurants and convenience stores. Information is provided on a census tract basis and relates both to household economic conditions and availability of private transport for commuting [4] (Fig. 1).

Under USDA criteria defining low access food areas, "about 10 percent of the 65,000 census tracts in the United States meet the definition of a food desert. These food desert tracts contain 13.5 million people with low access to sources of healthful food. The majority of this population -82 per cent - lives in urban areas"[5]. According to USDA, "tracts qualify as 'low access' if at least 500 persons or 33 percent of their population live more than a mile from a supermarket or large grocery store (for rural census tracts, the distance is more than 10 miles)". Conventionally, the maximum distance from a 'full service grocer' has been established of 1-2 miles in urban areas and 10 miles in rural areas. Such a relevant snapshot of the current situation meets somehow public concern and media attention to the environmental impacts of food, namely life-cycle greenhouse gas emissions associated with food production, since in the US food is prevailingly transported long distances (1640 km delivery and $6760 \mathrm{~km}$ life-cycle supply chain on average) [6]. Current debate is moving towards short food supply chains, with short distance and/or small number of intermediaries between producers and consumers. It entails a broad range of food productiondistribution-consumption configurations, such as farmers' markets, farm shops, collective farmers' shops, community supported agriculture, solidarity purchase groups.

In this context, the United States is at the forefront of community-based agricultural and rural practices, not only for the achievement of urban physical regeneration objectives, but also in consideration of the social integration and economic development targets that such initiatives aim to attain. In fact, together with the most renowned 'community gardens' or 'retail farms', there is a wide variety of different activities linked to local agricultural production and fresh produce as 'commercial kitchens', food business incubators or culinary art initiatives integrating the healthy dimension with job creation, community education, culinary culture and related socioeconomic aspects.

Planning agencies, both at local and regional level, are increasingly using urban and regional plans to address food system issues in a sustainable way. Among them, UA is one of the topics identified as an 'innovative' tool to enhance the food system, economically, environmentally and mostly socially. Defined as "the growing, processing, and distribution of food and other products through intensive plant cultivation and animal husbandry in and around cities" [7], UA includes a number of different green- and brown-field initiatives. These projects are often inspired by NPOs with a variety of goals, including health and environmental issues, and job and income creation, as well as the development of entrepreneurial skills and the regeneration of distressed neighbourhoods. Indeed, as cities spread into suburbs, inner-city buildings and lots are abandoned or demolished; UA restores vacant parcels of land to productive use in an alternative food supply mechanisms.

\section{The California model. Entanglement of policies, strategies, actors}

In the last few years, the State of California has launched a new series of policies to promote a culture of healthy eating and access to fresh and nutritious food. The California Healthy Food Financing Initiative Council (CHFFIC) was established in October 2011 when the Governor signed Assembly Bill (AB) 581. CHFFIC is a public-private partnership program that was created to increase access to healthy foods in underserved, urban, and rural communities and inspire innovation in healthy food retailing. The CHFFIC Fund - using federal, state, philanthropic, and 
private funds - provides financing for grocery stores and other forms of healthy food retail and distribution by delivering grants and loans to eligible applicants.

In California, particularly large metropolitan areas are currently making 'foodshed' assessments to plan for specific interventions. In the last years cities as San Francisco, Los Angeles and San Diego have been easing procedures and changing plans and zoning codes to include UA and stimulate the cooperation of NPOs and other local actors. In particular, The California Endowment (TCE), a private, state-wide foundation whose mission is to provide access to affordable, quality health care for underserved individuals and communities in California, is undertaking the Building Healthy Communities Initiative, a 10-year, \$1 billion plan that funds 14 Californian communities in order to transform their neighbourhoods.

TCE granted funds to start the San Diego County Food System Alliance in March 2012. The Alliance's objectives are to strengthen local farms and improve access to high-quality healthy local food by improving infrastructure and regional food distribution.

The UA approach is currently gaining space in San Diego within both the wider political framework and the cultural shift towards more healthy eating habits and food, especially in lowincome communities. UA in its various forms may therefore be seen as a complementary, concurrent element - if not a trigger - of economic and social regeneration initiatives in blighted areas and distressed communities.

Actions and initiatives related to UA take different forms and have been institutionally recognized both by the County of San Diego in its Strategic Plan (2012) and the City of San Diego in its municipal and zoning codes: the amendments adopted in January 2012 enhance the 'zero food miles' approach by introducing two new categories within the General Plan ('Farmers' Markets' and 'Retail Farms'), simplifying the process for approving farmers' markets on private property, making minor adjustments to community garden regulations, and easing restrictions for keeping small animals (chickens, goats and bees) in single family and multi-family homes. Under the amendments, retail farms (produce is grown and sold at the same location) are differentiated from daily, weekly and monthly farmers'markets, under distinct rules. Within the context of land use zoning, community gardens and backyard gardens are regarded as primarily for consumption by the grower, while commercial urban farms are for production and selling.

The amendments follow a $\$ 50,000$ grant awarded to the City by the County of San Diego Health and Human Services Agency in order to pursue municipal code and general plan amendments supporting UA with the goal of stunting obesity rates by planning communities in ways that support increased physical activity and access to healthy foods.

Definitively, within the amended General Plan in San Diego, UA is defined as "the production of food in and around cities for local consumption". The policies of specific plans aim towards a UA system that should be both economically and environmentally sustainable by:

- encouraging the use of specific UA techniques that require reduced land and water use;

- recognizing the cultural and economic benefits of providing opportunities for residents to grow healthy, affordable, culturally appropriate foods;

- developing land development regulations that allow UA uses in appropriate locations and increase opportunities for farmers' markets on public and private land;

- encouraging UA land use in underutilized vacant plots and peri-urban areas;

- exploring potential locations for UA land use as part of a long range plan.

\section{City Heights neighbourhood and 'New Roots Initiative'}

Besides public support, other funds are available thanks to private and non-profit bodies advocating for health and health equity, and fighting to expand access to affordable, quality health care for underserved communities. Among them, TCE fund, previously mentioned, is active since 1996; it has appointed Social Compact, NPO of the business sector, for highlighting through a detailed survey the discomfort of City Heights neighbourhood in San Diego, marked by pockets of poverty, illegal immigration and unmet demand in public and private transportation [8]. Over the past few years, Social Compact has worked to develop the Grocery Gap analysis, a research 
methodology that addresses critical questions regarding grocery and food access options in communities nationwide; the tool is able to quantify the demand for grocery services, understanding when there is mismatch, and to highlight what it means to be an underserved neighborhood, measuring a community's access and the availability of grocery services.

On average, residents in the City Heights study area (Population 90,577; Households 26,944) travel a distance of 0.66 miles to reach one of the seven full service grocers in the whole area, yet in some block groups residents travel a greater distance, nearly double the study area average (Fig. 2). About 33 percent of the total population reside in 'critical food access areas' and roughly 24 percent reside in areas considered underserved, many of which demonstrate market potential that could support additional grocery retail development.

A more detailed analysis of critical food opportunity areas and density can enhance understanding of where need for grocery development is more acute and likely to impact a greater proportion of underserved residents. Still, such a 'view from above', while providing quantitative data related to food access, neglects several qualitative features that could prove assets in a placebased approach. City Heights is largely defined by its prominent topography: settlements sit primarily atop mesas punctuated by impressive canyon systems and creeks. Density varies from 47 people per acre (120 inh/ha) to 8 people per acre ( $20 \mathrm{inh} / \mathrm{ha})$.

Whereas a higher density proves a competitive advantage typical to urban markets, low density could enhance a different consumption pattern related to short food supply chains: at a closer look, urban agriculture and urban farming could easily be accommodated in vacant lands, also considering that husbandry complies with previous activities of the many immigrants communities, notably several refugee groups from Somalia, Vietnam, Cambodia.

Access to affordable fresh and healthy food has become a major issue, all the more so because immigrants and refugees tend to prefer food from their own culture, which may be very difficult to obtain in an already underserved area. This too must be taken in consideration, as the majority of affordable groceries throughout the whole city of San Diego are from the Mexican culinary tradition.

The International Rescue Committee (IRC) - an important international NPO working with a peculiar focus on refugee resettlement in the US - gained better awareness of the food-related problems in the City Heights neighbourhood and began organizing meetings with local communities around this issue. Many immigrant families suffered high rates of obesity and other health problems due to the lack of affordable fresh and healthy food.
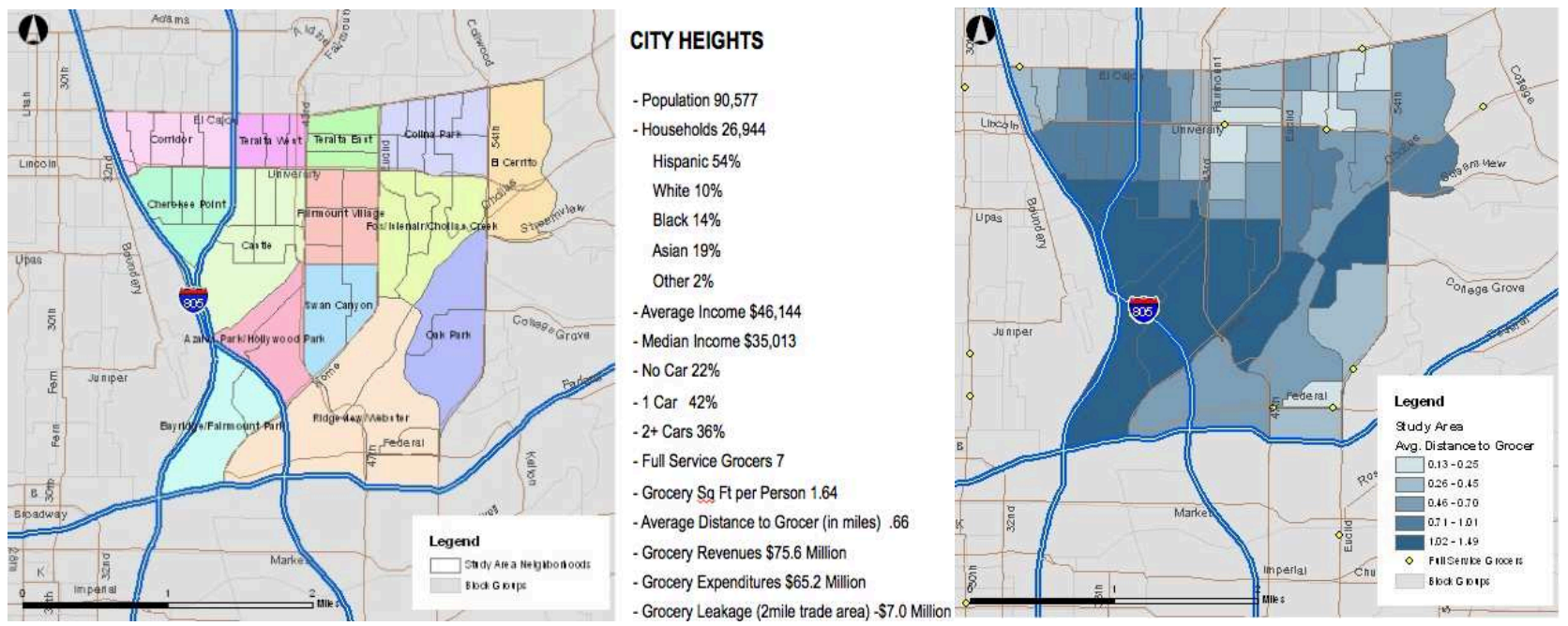

Fig. 2. San Diego City Heights Grocery Gap. Study Area Context Map (left) and Average Distance to Full Service Grocer by Census Block Group. Source [8]. 
IRC started a bottom-up process, working with refugee communities, other residents and local groups to tackle food insecurity and malnutrition. They identified a vacant brownfield public lot and asked the city for permission to farm that land. Because the City did not yet have a policy for urban farming, IRC - together with residents and non-profit advocates - focused on finding solutions by promoting changes in the laws about land use, community gardens, farmers' markets and other grassroots initiatives.

After several years of bureaucratic process, in 2009 the City of San Diego approved the project and released an 'occupancy permit' on the designated vacant plot. As already mentioned, a significant development in this process was the approval of a city ordinance in January 2012 that dramatically streamlined the city's community garden regulations.

Since many refugees were farmers in their countries of origin, the strategy was less oriented towards technique, and more towards a better understanding of market dynamics, business and marketing.

The New Roots Community Farm, endorsed by the First Lady Michelle Obama visiting the garden in 2010, is the first of several initiatives put in action by IRC under the broader umbrella of the Food Security and Community Health (FSCH) Program (Fig. 3. - 4.).

Other initiatives comprise the New Roots Aqua Farm, an 'aquaponics system' that employs a closed-loop cycle of tilapia farming with hydroponic vegetable growing. The Aqua Farm is also a small-food-business incubator that gives entrepreneurial residents additional space to grow.

New Roots growers from both the Community and Aqua Farms sell their produce on a weekly basis at the City Heights Farmers' Market. Within the same program, the City Heights Community and Remedy Garden is located in the heart of City Heights with 16 gardening plots for community residents and a herbal medicinal garden, where two high school garden programs train youth in urban farming and food justice advocacy.

This incremental strategy is to ensure that refugees and residents are able to obtain affordable fresh organic food to feed themselves and their families, and also gradually to introduce them to the food business. Training programs are organized by the IRC, and because the community farm has been certified, they are able sell their surplus at City Heights Farmers Market and to restaurants, making it a potential secondary income for a family. This is especially pertinent to women, who generally are more involved in the process. Some farmers have turned this activity into a business, through a food business incubator located in Pauma Valley, 50 miles into San Diego County.
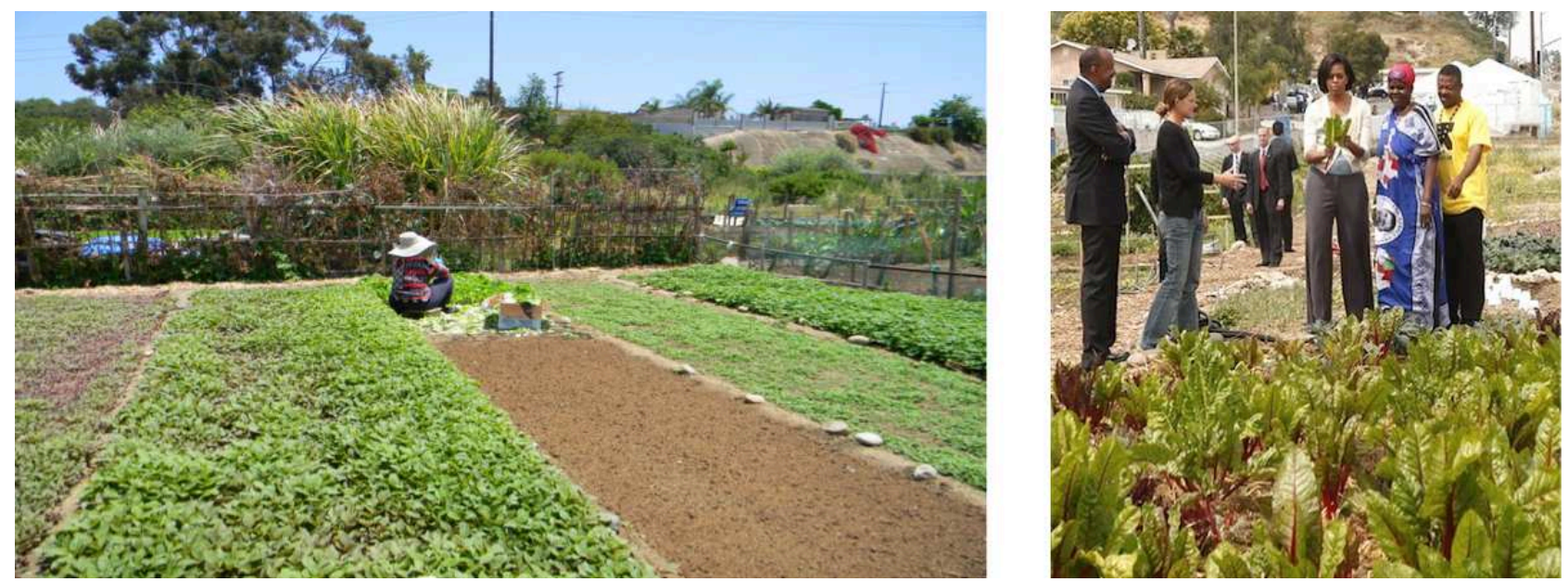

Fig. 3. - 4. Refugees working in the community garden (left) and First Lady Michelle Obama, visiting 'New Roots Community Farm', San Diego, April 15, 2010. (Photos A. L. Palazzo 2013, left, and Associated Press 2010, right.) 
From a micro point of view, the initiative is proactive in meeting its community needs, primarily in terms of food security and nutrition. In a 'critical food access area' such as City Heights, farmers not only have land to farm and access to fresh ethnic food, but also technical assistance, credit facilities and training to improve their business knowledge. Locally grown food from New Roots may allow households to enhance their income and achieve a better diet. Training programs improve business capacity building, and microenterprises are sustained by a number of IRC facilities.

Broadening the perspective, New Roots has widened its specific impact via a step-by-step process, and now comprises a network of initiatives serving communities' needs, and developing local economies both within the neighbourhood, and beyond its urban borders.

\section{Food potential for regenerating our living environments}

As it is increasingly argued by different stakeholders interacting in urban and regional domains, there is no doubt about the growing attention on the 'Healthy food policy' general framework, from the conception of programs and plans to the implementation and management of projects.

It is at the moment a core problem not only for the specific condition of developing countries, but also for the US and other OECD countries, where food issues are more and more linked to cities, prompting new governance tools. As an example, for some Authors, the term 'foodshed' conveys somehow the idea of a model food basin for production and consumption according to the needs of an estimated resident population [9]. Beyond the paradoxical defiance in such a 'global economy', it should be noted the role that UA plays against the reduction of the ecological footprint and/or the raising of market price of fruits, vegetables and dairy products.

However food issues are increasingly matching with other concerns related to land use and land consumption notably in fringe areas where the urban and the rural have become increasingly difficult to differentiate. Indeed, "the fringe is not just the place where town meets country but a collection of dynamic and productive environments set in inspiring cultural landscapes, meeting the needs of both the present and helping to change the way we live in the future" [10].

Tackling 'urban rural-fringe' areas means to cope with: "a multi-functional environment, often characterised by essential service functions; a dynamic environment, characterised by adaptation and conversion between uses; low-density economic activity including retail, industry, distribution and warehousing; an untidy landscape, potentially rich in wildlife" [11], and, last but not least, with the management of urban growth by avoiding potential sprawl.

In the European countries ruled by the 'civil law' culture, notably in France, urban planning is incorporating strategic design tools along with specific sectorial policies including food system arrangements for health and sustainability (i.e. Politique Penap, Charte de l'Agriculture urbaine,...).

Conversely, in the US, and in California, UA is increasingly used to foster virtuous forms of cohesion and socially-inclusive strategies in contemporary fragmented metropolitan communities.

The case of San Diego conveys a series of suggestions both at central and local institutional levels. It proves the potential of a proactive set of initiatives in terms of actors, partnerships, social value, community involvement, economic sustainability, mixed functions, and new identities. Yet, although these themes are entangled in strategic documents - for instance the 'Farming Program Plan' which is one of the topics of San Diego County Strategic Plan - many professionals are fostering the promotion of the holistic character in plans, programs or projects aimed at developing a County's territory or a limited area. This character could allow local government to virtuously create a real added value.

On this way, recently William Fulton, who has been leading the San Diego city's Planning Department for 2011, is working to bring many single redevelopment programs and projects under the General Plan framework [12].

However, it would be an illusion to think that such a 'recipe' can be imported 'sic et simpliciter' into other contexts. In fact, its relevance as best practice is obviously related to specific conditions of space, time, and civic and juridical culture. 


\section{Acknowledgements}

This paper is related to the dissemination of the EU research project "CLUDs" (Commercial Local Urban Districts), Seventh Framework Programme, Marie Curie Actions People IRSES, 2011-2014. The program implementation is based on networking four EU universities (Mediterranea Reggio Calabria, "Sapienza" Roma, Aalto Helsinki, Salford Manchester) and two USA universities (Northeastern University Boston, MA and San Diego State University, CA). The paper was conceived and developed through a full cooperation of the Authors, nevertheless sections 1-3-4 are to be attributed to Bruno Monardo, and sections 2-5 to Anna Laura Palazzo.

\section{References}

[1] M. Nestle, Food politics: How the food industry influences nutrition and health, University of California Press, Berkeley, Los Angeles; London, (2007)

[2] K. Morland, A. Diez Roux, S. Wing: Supermarkets, other food stores, and obesity: The atherosclerosis risk in communities study, in American Journal of Preventive Medicine, 30, 4 (2006), pp. 33-39

[3] USDA (United States Department of Agriculture), Farm Bill 2008

[4] USDA ERS, Food Access Research Atlas (2012). Information on http://www.ers.usda.gov/dataproducts/food-access-research-atlas.aspx./

[5] USDA, Office of Communication, Release 0191.11 (2011). Information on http://www.usda.gov/wps/portal/usda/usdamediafb? contentid=2011/05/0191.xml\&printable= true/

[6] C. L. Weber, H.S. Matthews: Food miles and relative food choices in the USA, Environmental Science Technology, 42, 10, (2008), pp. 3508-3513

[7] M. Bailkey, J. Nasr: From brownfields to greenfields: Producing food in North American cities, Community Food Security News, Fall 1999/Winter 2000, 6

[8] Social Compact, City Heights Grocery Gap (2011). Information on http://midcitycan.com/

[9] Feagan, R., The place of food: mapping out the 'local' in local food systems, Progress in Human Geography, 31(1), (2007), pp 23-42

[10] A. et alii Scott: Disintegrated Development at the Rural Urban Fringe. Re-connecting spatial planning theory and Practice, Progress in Planning, 83, (2013), pp. 1-52

[11] N. Gallent, J. Andersson, M. Bianconi: Planning on the Edge. The context for Planning at the rural-urban Fringe, Routledge, London (2006)

[12] W. Fulton, P. Shigley: Guide to California Planning. Solano Press, Point Arena (CA), (2012) (fourth ed). 